\title{
Superando a arapuca do senso comum: turismo de ou em favelas? $O$ caso Vidigal - RJ
}

Overcoming the trap of the common sense: tourism of or in Favelas? The Vidigal Case- RJ

Superando la trampa del senso común: ¿ turismo de o em Favelas? El caso Vidigal- RJ

Fausi Kalaoum ${ }^{1}$

Este artigo foi recebido em 27 de FEVEREIRO de 2019 e aprovado em 17 de OUTUBRO de 2019

Resumo: Esse trabalho tem como objetivo principal analisar o turismo que ocorre na favela do Vidigal e criar um contraponto que desmitifique o senso comum que tende a compreender esse tipo de atividade como uma segmentação turística: o turismo de favelas. A crítica construída nesse trabalho, se materializa a partir do entendimento generalizado, socialmente construído, de que o turismo de favelas ocorre quase que exclusivamente para o consumo de pobreza e miséria, muitas das vezes materializados nos jeep tours ou até mesmo em tours de experiência. Assim sendo, a construção de uma visão genérica sobre as favelas e seus produtos turísticos é minimizada e suas formações sociais, geográficas e especificidades ignoradas em prol da marginalidade e pobreza. Esse trabalho, de caráter qualitativo, se manifesta em uma pesquisa exploratória em que foram utilizados os seguintes métodos: a pesquisa bibliográfica que trate de favela e turismo; a observação em campo; a aplicação de entrevistas a moradores do morro. Como resultado, essa pesquisa indica que há, além de pobreza a ser consumida no Vidigal: o consumo turístico, que acontece de maneiras variadas, tais como a busca de aventura, festas e eventos e a inserção cultural.

Palavras-chave: Favela; Turismo; Vidigal.

\begin{abstract}
This work has as main objective to analyze the tourism activity that occurs in Favela of Vidigal and create a counterpoint that demystifies the common sense that tends to comprehend this type of activity as a touristic segmentation: Tourism of favelas. The critiques built up in this work materializes themselves from the generalized understanding socially constructed of what the tourism in Favelas occurs almost exclusively to the consumption of poorness and misery, many times materialized in jeep tours and even experience tours. Thus the construction of a generic point of view about favelas and their respective products is minimized and their social and geographical formation and specificities ignored in favor of marginality and poorness. This qualitative work manifests itself in an exploratory research in which it was utilized the following methods: bibliographical research that works about favela and tourism; field observation; interview application to locals. As a result this research indicates that there is beyond poorness to be consumed in Vidigal: the tourism consumption happens in varied ways as such the adventure experience, events and parties and cultural insertion.
\end{abstract}

Key words: Favela; Tourism; Vidigal

${ }^{1}$ Informações do autor:

Formação/curso: Graduado em Turismo; Especialista em Gestão de Cidades e Planejamento Urbano; e Mestre em Desenvolvimento Territorial e Políticas Públicas Instituição: Universidade Federal Rural do Rio de Janeiro - UFRRJ Campus Nova Iguaçu; Universidade Cândido Mendes; Universidade Federal Rural do Rio de Janeiro E-mail: f.kalaoum@hotmail.com 
Resumen: Este trabajo tiene como objetivo principal analizar el turismo que ocurre en la favela del Vidigal y crear un contrapunto que desmitifique el sentido común que tiende a comprender ese tipo de actividad como una segmentación turística: el turismo de favelas. La crítica construida en ese trabajo se materializa a partir del entendimiento generalizado socialmente construido de que el turismo de favelas ocurre casi exclusivamente para el consumo de pobreza y miseria, muchas veces materializadas en los jeep tours o incluso en tours de experiencia. Así, la construcción de una visión genérica sobre las favelas y sus productos turísticos es minimizada y sus formaciones sociales, geográficas y especificidades ignoradas en pro de la marginalidad y pobreza. Este trabajo de carácter cualitativo se manifiesta en una investigación exploratoria en la que se utilizaron los siguientes métodos: la investigación bibliográfica que trate de favela y turismo; la observación en campo y la aplicación de entrevistas a los habitantes del cerro. Como resultado, esta investigación indica que hay más allá de la pobreza a ser consumida en Vidigal: el consumo turístico ocurre de maneras variadas, tales como la búsqueda de aventura, fiestas y eventos y la inserción cultural.

Palabras Clave: Favela; Turismo; Vidigal

\section{Introdução}

Depois de mais de um século entre serem reconhecidas e/ou manter seus territórios livres de remoções investidas pelos agentes do poder público municipal, as favelas do Rio de Janeiro começaram a desenvolver, no fim do século XX, um novo e inusitado papel dentro da cidade carioca: o de destino turístico (FREIRE-MEDEIROS, 2009).

Segundo Freire-Medeiros (2007), um dos acontecimentos que pôs as favelas em evidência ocorreu em 1996, no morro Santa Marta, localizado no bairro de Botafogo, Zona Sul do Rio de Janeiro, ao receber a visita do cantor Michael Jackson para a gravação do videoclipe da música They don't care about us (Eles não se importam conosco). A vinda de Michael Jackson a uma favela carioca causou rebuliço no cenário político brasileiro: o então governador, Marcello Alencar, acusou o cantor de querer interpretar o papel de rei dos pobres, e outros políticos tentaram, em vão, fazer com que a gravação do videoclipe não acontecesse. Não somente aconteceu, como também Michael Jackson ganhou uma estátua em tamanho real, além de um mosaico em determinado ponto do morro.

No Vidigal, favela também localizada na Zona Sul do Rio de Janeiro, entre os bairros do Leblon e São Conrado, a visita de uma "celebridade" antecedeu a vinda de Michael Jackson. Foi na década de 1980, que o Papa João Paulo II visitou o morro. Na ocasião, a vinda do pontífice mobilizou a população para a construção da primeira Igreja Católica local, que, posteriormente, ficou conhecida como Igreja do Papa e está localizada na área conhecida como "Catorze". Além da construção da igreja, houve também melhorias na infraestrutura do morro, de acordo com relatos de moradores.

Especificamente sobre o Vidigal, um dos marcos mais importantes para o turismo local ocorreu em Janeiro de 2012, com a instalação da Unidade de Polícia Pacificadora (UPP) no morro. A UPP, de acordo com o portal do governo estadual, é um programa de segurança pública que surgiu em 2008, elaborado com os princípios de Polícia de Proximidade e com objetivo da retomada permanente de territórios dominados pelas facções de narcotráfico (UPPRJ, 2017). Esse trabalho não tem como 
objetivo discutir a eficiência ou eficácia do programa, mas é a partir da implementação da UPP que ocorre uma intensificação do fluxo de visitantes (turistas e excursionistas) no morro e, concomitantemente, uma massiva expansão de ofertas turísticas e não turísticas, como o crescimento da rede de hospedagem (com predominância de hostels), locais para eventos, restaurantes sofisticados (com cardápio bilíngue) e outros. Esse fato pode ser observado por meio de visitas ao Vidigal que tiveram início em $2012^{2}$ e se estenderam até 2018. Se em 2012 existia na favela apenas três albergues, esse número chegou a 25 entre os anos de realização dos megaeventos esportivos - Copa do Mundo e Jogos Olímpicos, que ocorreram, respectivamente, em 2014 e 2016.

Em 2014, o Vidigal ficou novamente em evidência, quando uma das principais emissoras de canal aberto do Brasil utilizou a favela como cenário de uma telenovela em horário nobre, revelando para a realidade de milhares de espectadores um prisma completamente novo do historicamente estereotipado enraizado no senso comum de muitos brasileiros. Ao invés de lugar de violência e antro de marginalização, o Vidigal passou a ser conhecido como cenário de festas, realizadas principalmente pelo primeiro albergue aberto na favela localizada no ponto mais alto (Arvrão) que proporciona uma vista panorâmica dos bairros do Leblon e Ipanema e as suas orlas, além de vista para o Cristo Redentor. Ainda, acontecimentos de algumas celebridades internacionais, tais como David Beckham, jogador de futebol, e Madonna, cantora, que tem adquirido imóveis no morro, evidenciaram ainda mais a favela.

Com os marcos históricos que colocaram as favelas cariocas em evidência e os acontecimentos ocorridos no próprio Vidigal, o desenvolvimento desse trabalho se propõe a pôr em xeque e a responder se a pobreza seria ou é a principal forma de busca e consumo turístico por aqueles que visitam o morro, indo em sentido contrário ao senso comum e até mesmo a produção científica sobre o tema. Dessa maneira, esse trabalho tem como objetivo principal o de estimular o pensamento crítico e desconstruir o senso comum que paira na literatura científica e midiática a respeito da atividade turística nas favelas. Nesse sentido, as leituras, com frequência, enfatizam a pobreza como único e/ou principal produto a ser consumido nas favelas, homogeneizando os espaços, criando distorções (MADUREIRA, OLIVEIRA, IRVING e TAVARES, 2018) e reforçando preconceitos e imagens mentais preestabelecidas, submetendo, como enfatiza Frenzel (2013), seus moradores a estigmas sociais e discriminação.

\footnotetext{
${ }^{2}$ Visitas realizadas para composição de um inventário turístico e, posteriormente, transformado em Trabalho de Conclusão de Curso (em 2015) para a obtenção da titulação de Bacharel em Turismo pela Universidade Federal Rural do Rio de Janeiro.
} 


\section{Marco teórico}

A leitura sobre o turismo nas favelas, seja acadêmica como encontrada em Nisbett (2017), Telles (2018), Bentes (2008) ou Freire-Medeiros (2007, 2009), ou em reportagens jornalísticas, artigos de opiniões e outros, exalta a pobreza como principal atrativo turístico e parece generalizar o turismo em favelas como turismo de favelas. Esse tipo de atividade parece ter o sinônimo de turismo de pobreza. No senso comum, se ousa dizer que não há distinção: visitar favelas é, necessariamente, buscar testemunhar a pobreza que é materializada em formas de tours ou jeep tours por empresas que estão alheias ao território geográfico dessas favelas e que visam testemunhar e/ou registrarem elementos que reforcem a marginalidade: "No imaginário político e social dos nossos tempos, assim como na cultura popular e de massa, as favelas têm sido tradicionalmente concebidas em termos negativos" (TELLES, 2018, p,303).

Há, por sua vez, uma fundamentação histórica para esse coletivo imaginário sobre as favelas como local de pobreza e abandono. Valladares (2005) elucida que os agentes do poder público do Rio de Janeiro entendiam os cortiços - construções que abrigavam, de maneira insalubre, dezenas e até mesmo centenas de pessoas - como antro de marginais e malandros:

Considerado o locus da pobreza, no século XIX era local de moradia tanto para trabalhadores quanto para vagabundos e malandros, todos pertencentes à chamada 'classe perigosa'. Definido como um verdadeiro 'inferno social', o cortiço carioca era visto como antro da vagabundagem e do crime, além de lugar propício às epidemias, constituindo ameaça à ordem social e moral. Percebido como espaço propagador da doença e do vício, era denunciado e condenado através do discurso médico e higienista, levando à adoção de medidas administrativas pelo governo das cidades (VALLADARES 2005, p.24).

Com a política higienista adotada pelos agentes públicos municipais do Rio de Janeiro no início do século XX, a erradicação dos cortiços deu lugar à ocupação dos morros, em especial aqueles localizados próximo ao centro da cidade, dando origem assim o que seria posteriormente denominada como favela. Apesar de cortiços e favelas serem coisas distintas, Gonçalves (2013) afirma que ambas eram vistas como locais de vagabundagem, violência e pobreza, e, apesar das definições criadas pelo $\mathrm{IBGE}^{3}$ e pela Secretaria Municipal de Urbanismo por meio do Plano Diretor ${ }^{4}(2009)$ mesmo não mencionando a violência, enfatizam o aspecto de precariedade e pobreza desses.

\footnotetext{
${ }^{3}$ De acordo com o IBGE, as favelas, ou Aglomerados Subnormais são constituídas por 51 ou mais unidades habitacionais caracterizadas por ausência de título de propriedade e pelo menos uma das características:
} 
Retomando Medeiros (2009), a pobreza acabou se tornando bem mercantil e sendo assim, consumida por uma classe mais abastada que se torna ávida pelo saber e pelo viver dos pobres. Ademais, a prática de visita a bairros pobres pelos ricos, também conhecida como slumming (slum na língua inglesa significa favela), teve seu auge entre os anos de 1880 e 1890 e logo após entrou em decadência, ganhando forças novamente somente após quase um século:

Isso significa que o turismo de favela, como nós conhecemos hoje, é relativamente novo e atualmente pouco pesquisado, com o corpo da literatura acadêmica apenas recentemente começando a tomar forma. Esse pequeno, mas crescente debate é dominado por discussões éticas. Alguns estudiosos apontam para o apelo voyeurístico do turismo em favela, refletindo no porqu das pessoas quererem visitar as favelas, qual prazer poderia ser derivado disso e se essas pessoas deveriam ser permitidas a visita-las (NISBETT, 2017, p.38)

A autora ainda argumenta que os moradores das favelas experienciam diversas privações, tais como a falta de água potável, redução de direitos civis, dificuldade de acesso à educação e saúde. Esses elementos, como constituintes da pobreza e vulnerabilidade, estariam então no rol de produtos a serem consumidos na favela? Esse trabalho, então, desenvolveu um questionamento central: há de ser a pobreza o principal elemento e produto a ser consumido turisticamente nas favelas? E mais: não seria a generalização das favelas como pontos de pobreza a descrição de uma realidade não real e até mesmo discriminatória?

Para Pierre Bourdieu (1989), a realidade do mundo não deve ser entendida como real, mas sim como relacional. Em outras palavras, a realidade real, muita das vezes não passa de um conjunto de informações e conhecimentos rasos que advém de outras fontes que não a relação direta com o objeto ou espaço estudado. Sendo assim, constrói-se um cenário distorcido e com informações que não dialogam, de maneira verossímil, com determinada realidade. Aplicando o conceito de Bourdieu no Vidigal, podemos entender o porquê do senso comum de um imaginário que retrata as favelas unicamente como lócus de pobreza e marginalização. Barbas e Graburn, sobre a criação do imaginário turístico, afirmam o seguinte:

irregularidade das vias de circulação e do tamanho e formas dos lotes e/ou carência de serviços públicos essenciais (como a coleta de lixo, rede de esgoto, rede de água, energia elétrica e iluminação pública)

${ }^{4}$ Já o plano diretor da cidade (2009) do Rio de Janeiro classifica da seguinte maneira: $\S 3^{\circ}$ Entende-se por favela a área predominantemente habitacional, caracterizada por ocupação clandestina e de baixa renda, precariedade da infraestrutura urbana e de serviços públicos, vias estreitas e alinhamento irregular, ausência de parcelamento formal e vínculos de propriedade e construções não licenciadas, em desacordo com os padrões legais vigentes. 
O imaginário turístico representa uma parte específica da visão de mundo dos indivíduos ou de grupos sociais, de outros lugares que não aquele de sua residência principal, referindo-se aqui a contextos territoriais nos quais podem ocorrer alguns tipos de atividades de turismo e lazer. $\mathrm{O}$ imaginário turístico promove também a transição entre o aqui e o distante, o próximo e o exótico, o conhecido e o desconhecido. Ele intervém decisivamente na viagem. Sem o imaginário turístico, que seleciona a partir de uma gama de destinos mais desejados, o mais atraente ou o mais encantador, não pode haver qualquer projeto de viagem. Com efeito, o papel do imaginário turístico é, neste sentido, incontornável, uma vez que ele permite aos indivíduos aproximar-se do lugar turístico em suas várias dimensões, sem que seja perdida sua dimensão material e simbólica (BARBAS e GRABURN, 2002, p.1, grifo do autor)

De maneira geral, a favela (unificada e homogeneizada em uma única imagem mental), é interpretada pela mídia, frequentemente, como local de pobreza e onde o Estado não foi eficiente a ponto de resolver o "problema" (MADUREIRA et al. 2018). A mídia, nesse sentido, reitera uma construção sociopolítica histórica que estigmatiza esses espaços de maneira pejorativa. Há de citar aqui o que Milton Santos conceitua como Universalidade Empírica. Essa representa o estado de globalmente conectados em que a sociedade, em escala global, se encontra graças aos avanços tecnológicos. É por meio da Universalidade Empírica que as informações são difundidas e recebidas quase que instantaneamente. Contudo, leva-se em consideração que essas informações são, muitas das vezes, formatadas ou filtradas para expressar algo que seja de interesse daqueles que comandam os meios de comunicação. Assim, regularmente as favelas seguem sendo retratadas exclusivamente como arenas de extrema violência e subdesenvolvimento.

Apesar da pobreza não ser encarada por muitos como um produto turístico a ser consumido, se salienta que a atividade turística produz novos símbolos e códigos culturais e que a própria não se baseia apenas em atrativos naturais e/ou culturais somente. Portanto, há destinos turísticos que produzem seus elementos a serem consumidos por meio de intervenção antrópica ou até mesmo fruto de um acúmulo histórico de ações. Serrano esclarece da seguinte maneira:

É uma atividade que não depende mais exclusivamente da "vocação natural" de uma região, pois pode ser construída artificialmente e pelo poder econômico e político, pela criação de parques temáticos, de uma natureza artificial, de uma autenticidade histórica reinventada para saborearmos costumes, hábitos e tradições sociais que foram perdidos na corrida frenética para obter um papel no processo de globalização contemporâneo. [...] Não importa se a função social de determinadas formas e práticas não é a mesma: o turismo reinventa e cria novas funções, recupera antigas práticas e bens culturais por meio do folclore, e monta atrações turísticas para a região (SERRANO, 2000, p.106) 
Não se nega, nesse trabalho, que o consumo da pobreza se materialize como um produto e uma prática nas favelas cariocas que recebam fluxos turísticos - incluindo o Vidigal -, mas esta pesquisa revelou que há mais do que apenas a pobreza nas favelas. O fenômeno turístico se manifesta de maneiras diferentes em lugares diferentes. Ademais, o espaço, como nos afirma Milton Santos (2006), é um conjunto indissociável de sistemas de objetos e sistemas de ações, e é seguro afirmar que nenhum espaço é idêntico ao outro (apesar de apresentar similitudes). Partir desse pressuposto é negar que o fenômeno turístico se manifesta exatamente nos mesmos moldes em qualquer lugar, seja no Vidigal, Rocinha, Babilônia, Providência ou outra favela. Cada uma dessas possui uma constituição própria do espaço, marcado pela produção de sujeitos e instituições distintas ao longo do tempo, ou seja, o espaço é, na verdade, a resultante temporal de ações dos homens. Tempo e Espaço são, tão logo, fundamentais para compreender o nosso objeto.

\section{Metodologia}

Esse trabalho é fruto da Dissertação de Mestrado, intitulada pelos usos e abusos do Turismo no Vidigal: Territórios e atividades turísticas no morro pós UPP (2012/17), defendido e aprovado no Programa de Pós-Graduação em Desenvolvimento Territorial e Políticas Públicas (PPGDT) na Universidade Federal Rural do Rio de Janeiro (UFRRJ) em agosto de 2018. A dissertação em questão é o amadurecimento da monografia intitulada o Sistema de Turismo do Vidigal, apresentada e aprovada como um dos requisitos para obtenção do título de Bacharel em Turismo, curso oferecido pela UFRRJ campus Nova Iguaçu.

A pesquisa realizada, neste trabalho, teve objetivo exploratório que se deu pelo caráter exclusivo que trate o turismo no Vidigal, a partir de uma abordagem crítica, e que negue grande parte da literatura de turismo em favelas que tratam, quase que exclusivamente, de pobreza e miséria. Sendo uma pesquisa qualitativa, esse trabalho se debruçou com maior esmero em informações da realidade e não em números.

Em relação às técnicas de pesquisa, foram adotados os seguintes procedimentos: revisão bibliográfica que trate do tema de turismo e favelas.

Em estudo de campo, foram realizadas entrevistas semiestruturadas com quatro moradores do Vidigal. As entrevistas tiveram como objetivo identificar a busca e o consumo turístico por aqueles que visitam o Vidigal, a partir da visão dos locais. 
Outra técnica utilizada foi aplicação de questionários semiestruturados aos turistas que visitam o Vidigal. O objetivo de aplicar esses questionários foi a identificação de alguns fatores, tais como motivação de visita a favela, tempo de permanência, assiduidade de visitação, locais frequentados, relação pessoal com os moradores e outros. Contudo, nesse trabalho, serão apresentados dados apenas de motivação, visitação e consumo.

Por fim, a observação em campo foi utilizada como técnica para reforçar o rigor metodológico, visto que apenas quatro moradores foram entrevistados. Dessa maneira, essa técnica foi empregada para dar consistência ao rigor metodológico e dar validade aos dados coletados, tanto nas entrevistas quanto nos questionários.

\section{Resultados}

Organizar o conhecimento não é tarefa simples. Isso por que, de acordo com Morin (2005), esse processo deve operar por meio de seleção de dados significativos e a rejeição de dados não significativos. $\mathrm{O}$ autor ainda vai além a respeito da construção do conhecimento:

Separa (distingue ou disjunta) e une (associa, identifica); hierarquiza (o principal, o secundário) e centraliza (em função de um núcleo de noçõeschave); essas operações, que se utilizam da lógica, são de fato comandadas por princípios "supralógicos" de organização do pensamento ou paradigmas, princípios ocultos que governam nossa visão das coisas e do mundo sem que tenhamos consciência disso (MORIN, 2005, p.10)

Assim, organizar o pensamento requer, concomitantemente, a seleção e a rejeição de determinados dados. Em um trabalho na área das ciências sociais aplicadas, onde se trabalha a subjetividade, a seleção desses dados passa, inevitavelmente, por uma maior influência do pesquisador que pode alterar ou comprometer o resultado final da investigação. Objetivando alcançar dados relacionais da realidade, buscou-se compreender a perspectiva local do entendimento do consumo por aqueles que visitam o morro, foi feito o seguinte questionamento a quatro moradores: "O que os turistas buscavam ou buscam no Vidigal?". Salienta-se que, da amostra entrevistada, dois deles estão diretamente ligados ao trade turístico, sendo na época proprietária de um dos hostels pioneiros do morro e o segundo guia de turismo local. Já outros dois moradores t êm profissões não diretamente ligadas ao turismo. A escolha desse universo misto se justifica, pois se considerou importante levar em consideração diferentes perspectivas para o resultado dessa pesquisa. O parágrafo abaixo transcreve as respostas obtidas de maneira integra:

"Buscam relacionamento, interação com os nativos, cultura (Proprietária de Hostel, entrevista concedida 16/09/2017)" 
"Há diferentes perfis: alguns buscam a vista. Outros, uma hospedagem mais barata. Outros, as festas e alguns tantos, conhecer as favelas pelo ponto de vista dos locais e fora das esteriotipações" (Guia local) (entrevista concedida em 06/09/2017)

Na maioria das vezes, os turistas vêm em busca de um lugar que seja, muitas vezes, eu acredito que os turistas vêm ao Vidigal, como, no geral, uma comunidade ou uma favela, com um olhar exótico, sabe? E que, muitas vezes, incomoda muito a gente. O Vidigal, ao contrário da Rocinha, aqui do lado, é uma comunidade muito pequena. Tem uma única rua principal. $\mathrm{Ou}$ seja, a gente tem muita dificuldade em relação a trânsito, a locomoção em determinados horários, ou seja, uma comunidade relativamente já inflada só com quem mora aqui, enfim. Então quando o turista vem pra cá, ele também traz um certo desconforto pra quem é morador, porque, por exemplo, algumas casas fazem festas. Tem festas e as festas acabam resultando, é.. é prejudicial a comunidade, porque imagina: uma casa de festas que funciona de quinta a domingo toda noite até seis horas da manhã, cinco da manhã. Quem mora ao lado não dorme, não dorme nunca mais. E não é só isso né? Depois que as pessoas saem das festas, em geral, saem alteradas, então tem todo esse trajeto até a Niemeyer que seja. Então, tudo isso afeta a comunidade, que, de certa forma, é bem pacata. O Vidigal tem um ar bem de interior assim, uma mistura de interior com subúrbio. Por outro lado, assim, os nossos vizinhos aqui: Leblon, São Conrado, Ipanema, Gávea, não nos visitavam. Hoje em dia todo mundo sobe. Se você for na trilha Dois Irmãos, tá interditado porque tá cheio de gringo. É um espaço que só a gente ia, só morador ia porque, primeiro, que ninguém subia no Vidigal, quiçá subir no Dois Irmãos, então era um, quase que um lugar particular que hoje em dia é tomado pelos visitantes, pelos turistas e que, de certa forma, diretamente, para a comunidade, não acredito que traga tanta benfeitoria quanto deveria ser." (ator local) (entrevista concedida em 18/09/2017)

"Então, o turista busca os eventos que acontecem aqui no Vidigal nos finais de semana. Os bares que têm vistas maravilhosas para as praias da Zona Sul. Tem também a trilha que o movimento é grande da trilha. Eles vêm pra conhecer, né, cara? Gente de fora vem pra conhecer porque não tem uma comunidade tão linda, tão bem vista como essa aqui no Rio”. (garçom) (entrevista concedida em 02/10/2017)

Por se tratar de um guia local, o segundo entrevistado traz em sua resposta diversas motivações que levam os turistas ao Vidigal. Em primeiro lugar, está a apreciação da paisagem (tratada como "vista" no discurso). Nesse ponto, há de se assumir duas interpretações sobre a paisagem: a primeira como os elementos naturais apenas (em diversos locais do morro é possível ver a área litorânea do Rio de Janeiro, como as praias de São Conrado, Leblon, Ipanema, Arpoador, Barra, como áreas verdes de Mata Atlântica), ou o conjunto dos elementos naturais com as construções que ocupam o morro. Há, ainda, a busca de uma hospedagem mais barata, ou seja, são movidas por fatores econômicos. A Zona Sul do Rio de Janeiro é a área mais nobre da cidade, como uma grande 
quantidade de atrativos e recursos turísticos ${ }^{5}$ e, como consequência dessa valorização excessiva, os preços cobrados pelos serviços prestados (hospedagem, alimentação, transporte privativo) são mais elevados em comparação com outras áreas da cidade e adjacências (Zona Norte ou Baixada Fluminense, por exemplo). As festas mencionadas no discurso não são os tradicionais bailes funks que, tão comumente, ocorriam nas favelas antes do processo de pacificação, mas sim eventos com valores elevados de entrada (No Bar da Laje, por exemplo, a cobrança é, regularmente, entre R \$40,00 e R\$ 50,00, excluindo consumo) que acontecem em determinados espaços no morro (Laje do Neguinho, Alto Vidigal, Bar da Laje, Mirante do Arvrão). Pelo elevado preço de entrada e consumação (para o padrão econômico local), é seguro assumir que o público-alvo dessas não é o morador, e sim visitantes e turistas.

Parece essencial atrelar a essa discussão a resposta fornecida, pela primeira entrevistada, ao dizer "buscam relacionamento, interação com os nativos, cultura". No caso das festas, há um processo de segregação socioespacial onde não há relacionamento, interação com os nativos e tampouco ganhos culturais (visto que os bailes funks agora ficam restritos a aprovação do comando da UPP). A mesma ausência de interação ocorre na trilha Dois Irmãos, já que o contato com moradores locais daqueles que realizam a trilha se restringe a possibilidade de compra de alimentos e bebidas em dois pontos distintos da caminhada (como já tratado no capítulo 1). Temos, portanto, uma relação que se apresenta de maneira estritamente comercial. A resposta da primeira entrevistada se manifesta, de maneira genérica, ao assumir que todos aqueles que visitam a comunidade têm o objetivo específico de interação com os moradores locais, bem como conhecer sua cultura. Nesse quesito, o segundo entrevistado apresenta maior detalhamento e cuidado em sua resposta ao separar os diferentes perfis de turistas que visitam o morro.

É prudente assumir, nesse ponto, que, apesar da segmentação "turismo em favela", "turismo em comunidade" ou ainda "turismo de pobreza", há intenções e interesses diversos daqueles que decidem visitar esses locais. Isso porque, apesar de as favelas ou ex-favelas - recentemente transformadas em bairros, por decisão dos agentes do poder público municipal- estarem relacionadas à situação de vulnerabilidade socioeconômica ambiental e isto pode emergir como atrativo e até mesmo produto (e, nesse caso, há o consumo da pobreza), outros atrativos e produtos podem ser consumidos além do "turismo de experiência da pobreza" nesses lugares:

${ }^{5}$ Há autores (Barreto) que classificam atrativos e recursos como sendo sinônimos. Esse trabalho considera, como recursos, o patrimônio natural ou cultural que seja factível de se inserir na atividade turística. Já atrativo pode ser interpretado como o recurso que teve algum tipo de intervenção antrópica (geralmente ligada à infraestrutura de acesso). 
De fato a atração da pobreza é diretamente ligada a percepção romantizada do pobre, um senso de autenticidade que turistas esperam encontrar lá, e idealizações de uma vida simples que muito circulam nos discursos ocidentais sobre os outros (mais pobres) (FRENZEL, 2013, p.24).

O site agência Preview lista como atrativos da Rocinha: mata verde, morros de pedra lisa, praia e um forte sentimento de comunidade. No Vidigal, é possível identificar esses produtos a serem consumidos a partir das falas do segundo e terceiro entrevistados ao mencionarem "festas" e "a trilha do Dois Irmãos", “a vista” (como paisagem, elemento natural apenas).

O entrevistado 3 inicia a sua resposta por meio de uma premissa: a busca dos turistas pelo exótico. No contexto apresentando, contudo, o exótico surge como valor pejorativo vinculado ao atrativo buscado pelos turistas. A partir de sua fala, esse produto seria a favela em si. Nesse sentido, todo e qualquer elemento (humano, não-humano, físico e as relações autóctones e alóctones) é importante na construção desse atrativo. Para Freire-Medeiros (2009), a pobreza acabou se tornando um bem mercantilizado e, sendo assim, consumida por uma classe mais abastada que se torna ávida pelo saber e pelo viver dos pobres. O consumo da pobreza como produto turístico é perceptivelmente negativo ao terceiro entrevistado, dada carga negativa da palavra "incomoda" presente em sua fala. Além disso, há também preocupações referentes à infraestrutura (dificuldade em relação ao trânsito), ordem (não dorme nunca mais) e uso do território (algumas casas fazem festas, é tomado pelos visitantes).

A fala do quarto entrevistado articula-se com a do terceiro em relação aos usos dos lugares (nessa fala não é possível perceber uma concepção territorial clara, como é identificada na fala do terceiro entrevistado) e do consumo dos produtos e atrativos. O uso dos adjetivos, tão linda, tão bem vista transmite a ideia de aprovação do fluxo turístico. Há uma ênfase no sentido humano da visão, de apreciação do belo ("vistas maravilhosas"), da exposição para os que vêm de fora.

Um panorama geral das falas dos entrevistados demarca os atrativos e produtos que são buscados pelos turistas e excursionistas que adentram o morro. $\mathrm{O}$ quadro, a seguir, sintetiza a fala de cada um deles. 
Quadro 1-Produtos e atrativos do Vidigal de acordo com os entrevistados

\begin{tabular}{|l|l|l|l|l|}
\hline Entrevistado & Produto/atrativo & Produto/atrativo & Produto/atrativo & Produto/atrativo \\
\hline 1 & Interação/cultura & & & \\
\hline 2 & Cultura & $\begin{array}{l}\text { Preços baixos de "Vista" } \\
\text { hospedagem }\end{array}$ & Festas \\
\hline 3 & Trilha Dois Irmãos & Festas & Pobreza & \\
\hline 4 & Trilha Dois Irmãos & Festas & \\
\hline
\end{tabular}

O quadro elaborado corrobora a explanação inicial desse trabalho: há algo além de pobreza a ser consumida turisticamente no Vidigal. Para além das respostas obtidas, somente um dos entrevistados mencionou, de maneira indireta, a pobreza como algo exótico buscado por aqueles que visitam o morro. O mesmo entrevistado, por sua vez, ainda elucidou as festas e a trilha Dois Irmãos como potenciais produtos a serem consumidos. Há, assim, a presença de atrativos e potenciais produtos turísticos de ordem natural, social, cultural e econômica (preços baixos de hospedagem), de acordo com as respostas obtidas.

É possível ainda observar a carga semântica (positiva ou negativa) nas falas dos entrevistados no que tange a busca dos turistas por algo a partir de marcadores linguísticos. O quadro a seguir demonstra tais marcadores:

Quadro 2- Marcadores linguísticos e carga semântica da fala dos entrevistados

\begin{tabular}{|l|l|l|}
\hline Entrevistado & Marcadores linguísticos & Carga semântica \\
\hline 1 & $\begin{array}{l}\text { Relacionamento, interação, } \\
\text { cultura }\end{array}$ & Positiva \\
\hline 2 & $\begin{array}{l}\text { Ponto de vista dos locais, fora } \\
\text { das "esteriotipações" }\end{array}$ & Positiva \\
\hline 3 & $\begin{array}{l}\text { Exótico, incomoda, desconforto, } \\
\text { prejudicial, afeta, tomado, (não) } \\
\text { benfeitoria }\end{array}$ & Negativa \\
\hline 4 & Maravilhosa, linda, bem vista & Positiva \\
\hline
\end{tabular}

Fonte: Dados extraídos das entrevistas realizadas entre 06/09/2017 e 02/10/2017

O quadro acima ajuda a corroborar com a ideia que o turismo produz efeitos tanto positivos, quanto negativos para os envolvidos diretamente ou não a ele; três entrevistados fizeram colocações positivas a respeito do turismo no Vidigal, sendo dois deles ligados diretamente ao trade (a proprietária do hostel e o guia local) e um não ligado (garçom). Assim sendo, afirmamos que os "resultados" da atividade turística impactam em diferentes escalas e intensidades a sociedade/comunidade por onde se manifesta. Observa-se que apenas o terceiro entrevistado identifica como um dos potenciais atrativos e/ou produto turístico a pobreza que marca sua fala com semântica negativa. 
Além da entrevista realizada com os quatro moradores do Vidigal, também foi aplicado questionários aos turistas (na aplicação, os excursionistas não foram levados em consideração como universo) a respeito de suas motivações e consumo dentro do morro. Foram entrevistados 16 turistas, entre brasileiros e estrangeiros, e entre os questionamentos levantados estão "motivação da viagem" e "busca de produtos turísticos", sendo os resultados respectivamente apresentados nas tabelas abaixo:

Tabela 1- Motivação da viagem

\begin{tabular}{|c|c|c|}
\hline & Frequência & Porcentagem \\
\hline $\begin{array}{c}\text { Visitar amigos e } \\
\text { parentes }\end{array}$ & 2 & 12,5 \\
\hline $\begin{array}{c}\text { Vontade de conhecer } \\
\text { qualquer favela }\end{array}$ & 2 & 12,5 \\
\hline $\begin{array}{c}\text { Vontade de conhecer o } \\
\text { Vidigal } \\
\text { especificamente }\end{array}$ & 4 & 25 \\
\hline $\begin{array}{c}\text { Busca de novas } \\
\text { interações sociais e } \\
\text { culturais }\end{array}$ & 1 & 12,5 \\
\hline $\begin{array}{c}\text { Procura de emprego } \\
\text { Hospedagem mais } \\
\text { barata que arredores }\end{array}$ & 2 & 6,3 \\
\hline Aventura & 2 & 12,5 \\
\hline $\begin{array}{c}\text { Conhecer um local ou } \\
\text { atrativo específico do } \\
\text { Vidigal }\end{array}$ & 1 & 12,5 \\
\hline Total & 16 & 6,3 \\
\hline Fonte: Pesquisa de campo $(01 / 03 / 2016-18 / 02 / 2018)$ \\
\hline
\end{tabular}

Notamos, que entre os entrevistados, a maior frequência de motivação da viagem foi a de conhecer especificamente o Vidigal (enquanto dois dos entrevistados afirmaram que tinham a intenção de conhecer qualquer favela). Nossas análises até aqui apontam que o Vidigal já se constitui enquanto favela turística na cidade do Rio de Janeiro e nos leva a acreditar que boa parte daqueles que pernoitam no Vidigal, tiveram a intenção de conhecer a favela e os elementos que a compõem incluindo os moradores, visto que a busca de novas interações sociais e culturais também aparece como motivo de viagem. Entretanto, será que o Vidigal, enquanto destino turístico, é vivenciado como um todo, ou apenas partes dele serve ao propósito da atividade turística? Para tentarmos responder 
isso, questionamos o que os entrevistados buscavam enquanto produto turístico e obtivemos os seguintes resultados:

Tabela 2- Busca por "produtos turísticos"

\begin{tabular}{|l|c|c|}
\hline & Frequência & Porcentagem \\
\hline $\begin{array}{l}\text { Contato com a natureza e } \\
\text { apreciação da paisagem }\end{array}$ & 4 & 25 \\
\hline $\begin{array}{l}\text { Conhecer a cultura local e } \\
\text { interagir com moradores }\end{array}$ & 9 & 56,3 \\
\hline Conhecer a favela & 1 & 6,3 \\
\hline Namoro e relacionamento & 1 & 6,3 \\
\hline Eventos e festas locais & 1 & 6,3 \\
\hline Total Fonte: Pesquisa de campo $(01 / 03 / 2016-18 / 02 / 2018)$ \\
\hline
\end{tabular}

Os elementos paisagem e cultura surgem como os principais motivos no quesito intenção de consumo de produto turístico, representando quase $81 \%$ dos entrevistados. Assim, a trilha Dois Irmãos, a Prainha, o Grupo Nós do Morro e a interação com a população local para o aprendizado da história e conhecimento da memória da comunidade estariam entre as principais atividades realizadas pelos turistas. Nota-se que nenhuma das respostas fornecidas está correlacionada ao consumo da pobreza ou miséria.

Nesse ponto, é preciso trazer a luz da reflexão duas informações: a pesquisa realizada para compor a dissertação que originou esse trabalho conclui que há uma distinção entre territórios turísticos e territórios não turísticos no morro. Os critérios utilizados para essa classificação foram: a intensidade e o uso turístico dos respectivos locais e a concentração de estabelecimentos turísticos e de apoio à atividade. Por exemplo, a trilha Dois Irmãos pode ser categorizada como território turístico, apresentando, inclusive, disputas territoriais por ponto de vendas de alimentos e bebidas entre os próprios moradores. Outro local com forte fluxo turístico é a localidade conhecida como Arvão, onde estão localizados os empreendimentos de maior porte como o Bar da Laje e o hotel (primeiro e até agora único nessa categoria de meio de hospedagem) Mirante do Arvrão. Por outro lado, subáreas do morro como Catorze e Jaqueira, onde há uma forte predominância residencial, é possível notar um menor fluxo de visitantes. Esse fato pode ser observado por meio da realização de um tour guiado nas áreas em questão e reforçado pelo discurso do guia responsável que afirmou serem raros os pedidos de guiamento pelas localidades quase que estritamente residenciais. 
A luz dessa informação nos direciona para outra análise: justamente nessas áreas com predominância residencial e escassez de lojas e empreendimentos - sejam turísticos ou não - onde é possível contemplar os traços de subdesenvolvimento e precária infraestrutura: casas com acabamento inferior as encontradas na avenida principal; maior quantidade de lixo disposto ao chão; esgoto a céu aberto; passagens estreitas e mais irregulares. Associar a informação de fluxos turísticos menores à esses locais reforça a ideia principal dessa pesquisa: a pobreza não é a principal procura e consumo turístico do morro do Vidigal. Quando questionados sobre conhecer determinados locais do Vidigal, a localidade do Catorze/Pedrinha/ Igreja do Papa apresentou a menor frequência de respostas positivas, sendo essas, justo as regiões visitadas pelo guia local e classificada de acordo com a pesquisa de dissertação como território não turístico, como representado na tabela abaixo:

Tabela 3-Conhecimento das localidades do Vidigal

\begin{tabular}{|c|c|c|}
\hline Local & Conhece O Local & $\begin{array}{c}\text { Não Conhece O } \\
\text { Local }\end{array}$ \\
\hline Prainha & 7 & 9 \\
\hline Dois irmãos & 9 & 7 \\
\hline Sitiê Ecológico & 5 & 11 \\
\hline $\begin{array}{c}\text { Catorze/Pedrinha/ Igreja do } \\
\text { Papa }\end{array}$ & 2 & 14 \\
\hline Arvrão & 3 & 13 \\
\hline Laje do Neguinho & 3 & 9 \\
\hline Bar da Laje & 7 & 11 \\
\hline Hotel Mirante do Arvrão & 3 & 13 \\
\hline Festas no Alto Vidigal & 3 & 13 \\
\hline Nós do Morro & 2 & 14 \\
\hline Praça do Vidigal & 9 & 7 \\
\hline Vila Olímpica do Vidigal & 2 & 14 \\
\hline
\end{tabular}

Fonte: Pesquisa de campo (01/03/2016 - 18/02/2018)

Nota-se, em contrapartida, que o morro Dois Irmãos, Praça do Vidigal, Prainha e Bar da Laje surgem com as maiores frequências positivas. Esclarece-se que a Praça do Vidigal surge nessa lista por ser a principal rota de acesso ao morro, sendo, muita das vezes, inevitável não transitar por ela ainda assim, alguns dos entrevistados alegaram não conhecer. A trilha Dois Irmãos e a Prainha surgem como atrativos naturais e o Bar da Laje, de maneira concomitante, como oferta e atrativo turístico (nesse último caso, o Bar da Laje produz fluxo que busca o turismo de balada/ festa).

Apesar de essa pesquisa concluir, de maneira categórica, que a pobreza está longe de ser a principal motivação para os fluxos de visitantes que chegam ao morro, esse dado da realidade não minimiza outra questão grave e recorrente em destinos turísticos: a forma exploratória na qual ocorre a atividade. Mas o que seria então esse turismo exploratório, de acordo com a perspectiva de quem ocupa posição de mantenedor do trade turístico no morro? A fala de um dos entrevistados é 
esclarecedora nesse ponto: "O turismo no Vidigal é exploratório, pois não centraliza o morador como agente da atividade turística". Turismo exploratório, portanto, não é aquele que tenha relação direta com a exploração da pobreza como produto, como pode se pensar em um primeiro instante, é, na verdade, a materialização da atividade que visa apenas obtenção de lucros, deixando de lado os aspectos socioculturais e ambientais que pode se desenvolver a partir do turismo.

No jogo de preposições que há no título desse trabalho, há ainda a possibilidade de acrescentar mais uma, em uma alternativa de um turismo mais sustentável e benéfico para o local onde se manifesta: Pensar em turismo com a favela parece ter sido a alternativa encontrada para os empreendedores do Grupo Nova Era.

No dia 16/02/2018, os sócios promoveram a festa de lançamento do grupo "Nova Era" - nesse evento o hostel Favela Experience foi renomeado para Nova Era - que tem como objetivo principal criar um turismo de experiência que estabeleça como elemento principal da experiência do turista com o morador. A Nova Era é uma empresa de turismo de impacto social e que tem como missão aplicar a atividade como ferramenta de desenvolvimento social. Segundo um dos sócios, é preciso reformular o atual modelo de atividade turística da favela, onde o visitante geralmente apenas sobe os Dois Irmãos e vai embora. Em suas palavras “(...)isso não é turismo, é uma visita a uma montanha”. Ainda de acordo com o discurso proferido na festa, a empresa tem como missão proporcionar um turismo diferenciado, pautado na base comunitária e que permite quebrar preconceitos e desenvolver a empatia.

A proposta para que isso ocorra está apoiada em um preceito socioeconômico. Em primeiro lugar, distribuir $70 \%$ do rendimento da empresa para a comunidade ,por meio da construção de uma rede que abriga projetos sociais, fornecedores locais, Organizações Não-Governamentais e empreendedores, onde cada um desses recebe uma porcentagem do trabalho realizado. O tour pela favela é realizado por Guias Locais, e não pelos donos do grupo (que são estrangeiros). O objetivo desse guiamento local não é apenas mostrar a favela, mas também transmitir um pouco da história individual de cada guia para o turista. A combinação de coliving e coworking, onde pessoas que trabalharam em áreas diferentes compartilham um espaço e ajudam um ao outro, faz parte do projeto de experiência da empresa. A ideia é trazer turistas para permanecer por, pelo menos, trinta dias no Vidigal e que, assim, esse faça uso dos bens e serviços locais. Isso representaria superar a atividade superficial que, atualmente, ocorre no morro e promover uma troca mútua entre autóctones e alóctones. 
A Nova Era criou parceria com a Companhia de Viagens G Adventure Canadá para a criação de projetos no Vidigal que são financiados pelo Planeterra. Entre esses projetos, há o de capacitação de guias e o desenvolvimento de artesanato local. Além da parceria com a G Adventure, a Nova Era concorre atualmente a um fundo da empresa Booking para o desenvolvimento sustentável do turismo. A empresa está entre os 10 finalistas e solicitou a quantia de 300 mil euros para desenvolver o turismo não apenas no Vidigal, mas também em outras quatro favelas ainda não definidas.

O grupo tenta redefinir o perfil de turista que vêm ao Vidigal e, como consequência, a práxis turística. A parceria com a G Adventure ajuda a garantir que os grupos que permanecerão, ao menos, por 30 dias no Vidigal possam conviver com os moradores do Vidigal e até mesmo desenvolver projetos sociais de maneira individual a partir de seus conhecimentos e aptidões (como o caso de um turista que tem lecionado aulas de tênis para crianças). No campo da ideia e do discurso, a práxis turística se materializaria no proposto pelos proprietários do grupo Nova Era, em um turismo com a favela, valorizando, em primeira instância, as relações humanas, as memórias e as histórias, e na favela, onde os elementos físicos e geográficos surgem como pano de fundo. O objetivo principal aparenta ser o máximo envolvimento dos moradores com o turista, sem a intervenção de grupos externos, o que garantirá, em teoria, o desenvolvimento humano e econômico dos envolvidos, materializando assim um turismo de base comunitária de fato.

\section{Considerações finais}

O processo de acumulação histórica que trata as favelas como espaços marginalizados, subdesenvolvidos, violentos e de extrema pobreza parece perpetuar e migrar quando se entendem essas mesmas favelas como destinos turísticos. Aqui, não se abordam apenas artigos de opinião ou da representação de uma mídia, muitas vezes, sensacionalista, como apontado no trabalho de Madureira et al. (2018). Leituras acadêmicas também identificam o turismo que ocorre nas favelas como a busca do consumo da pobreza, criando, assim, ainda que de maneira não intencional, uma segmentação turística: o Turismo de favelas.

Essa segmentação turística surge de maneira equivocada, pois, retrata, de maneira genérica e reducionista, a atividade nesses locais. Formata no imaginário, espaços homogêneos com "produtos" a serem consumidos como sendo os mesmos. Em geral, esses correspondem ao consumo da pobreza.

Aqui não se afirma como verdade absoluta (o que é verdade?) que a vontade de consumir pobreza ou condições precárias de infraestrutura não possa surgir como elementos para a escolha da viagem ou visita ao Vidigal. Fato esse, inclusive compartilhado por um dos entrevistados e também 
morador do morro, que trata, de maneira sutil, mas ainda negativa, a busca e o consumo turístico. O que se afirma é que esse elemento, o da pobreza, não é a principal forma de consumo do fluxo no Vidigal, desmistificando e desconstruindo a arapuca do senso comum sobre as favelas. Não apenas a observação em campo, bem como a aplicação de questionários e a análise das entrevistas ajudam a reforçar essa conclusão. Como bem realça Owen (2017), o mercado do "turismo de favela" pode ser considerado voyeurística e desumanizante, mas também, de maneira alternativa, uma alameda para solidariedade.

O que consome então o turista no Vidigal? Entender as estruturas da atividade turística e de seus fluxos foi extremamente necessário para a construção desse trabalho e a escolha de métodos contribuiu para responder esse questionamento. Para os moradores entrevistados, não há uma homogeneidade quanto ao consumo turístico, mas ainda assim é possível traçar algumas características: as festas com os atrativos naturais surgem como principal busca daqueles que visitam o morro. Fato esse comprovado pela observação em campo e reforçado pela aplicação de questionário aos turistas.

Em locais mais famosos, como o Bar da Laje, que conta com uma infraestrutura e serviço mais sofisticado - por exemplo, o transfer que opera buscando e levando os clientes em determinados pontos da Orla de Ipanema e Leblon - há um limite de clientes a ocuparem o espaço e diversas vezes essa ocupação atinge o máximo, impedindo quem esteja do lado de fora de entrar. Para aqueles que exclusivamente visitam o morro em busca de eventos ou "baladas", se identifica a experiência de um simulacro onde a realidade reproduzida não condiz com o entorno habitual. Não há, nesses locais, elementos que remetam a cultura, a história ou a memória da favela. O único referencial de favela torna-se a própria localização geográfica. Nas palavras de Baudrillard "Na verdade, já não é o real, pois não está envolto em nenhum imaginário. É o hiper-real, produto de síntese irradiando modelos combinatórios num hiperespaço sem atmosfera" (1991, p.8). Afirma-se, então, que o Vidigal Turístico se limita, na maioria das vezes, aos principais atrativos, que também são poucos (a trilha e a praia, como elementos naturais, e as festas como simulacros).

A trilha Dois Irmãos também apresenta intenso fluxo: em grupos grandes ou pequenos, individualmente, guiados ou não, a passagem de visitantes pela Vila Olímpica do Vidigal, principal acesso à trilha é constante. Ao fim da trilha, é possível vislumbrar um pequeno amontoado de pessoas, por volta de 30 a 40, onde bebem, conversam, batem foto, ouvem música etc. Já na Prainha, além da praia em si, há a opção da prática de alguns esportes radicais como o slackline, waterslackline e o surf. 
Por essa razão, apesar desse trabalho estimular a crítica que trate as favelas como um grupo homogêneo - negando, portanto, o turismo de favela -, compreende também que o turismo em favelas pode também representar uma prática exploratória, se manifestando então com característica mercadológica e contraditória: a favela surge tanto como elemento principal e secundário, na intenção de consumo e no consumo de fato, respectivamente.

Apesar de não se tratar do objetivo principal desse trabalho, parece válido criar a provocação final de que ir além do turismo em favelas é alcançar o turismo com a favela, onde grupos de interesse constituam as arenas de decisões e ações, construindo assim uma atividade com um olhar de dentro para fora e que leve em consideração alguns elementos, tais como a história, cultura, meio ambiente e o fator econômico, em pé de igualdade. No Vidigal, essa tentativa parece ter ganhado o primeiro passo a partir do Grupo Nova Era: de acordo com um dos idealizadores - um norte-americano - consiste em reconfigurar o elemento central do turismo no Vidigal: a favela deixaria de surgir como elemento principal, sendo substituída pela vivência do morador. Fato é que esse tipo de turismo seria pioneiro e poderia contribuir para uma expansão do "Vidigal Turístico", incluindo territórios abstratos que tragam elementos não tangíveis como a história e a memória como "formas de consumo". Essa nova forma de turismo no morro, pode, inclusive, se tornar o ponto de partida para novas pesquisas e pesquisadores do tema, futuramente.

\section{Referências}

BOURDIEU, P. O poder simbólico. Editora Bertrand, 1989

FREIRE-MEDEIROS, B. Gringo na laje. Rio de Janeiro: Fundação Getúlio Vargas, 2009

FREIRE-MEDEIROS, B. A favela e seus trânsitos turísticos. Rio de Janeiro: 2007

FRENZEL, F. Slum tourism in the context of the tourism and poverty (reliefe) debate. Journal of the Geographical Society of Berlin, 2013.

GONÇALVES, R . Favelas do Rio de Janeiro: História e direito. Rio de Janeiro: Editora PUC, 2013.

IBGE - Instituto Brasileiro de Geografia e estatística. Aglomerados subnormais: informações territoriais

Disponível

em: 
https://ww2.ibge.gov.br/home/presidencia/noticias/imprensa/ppts/00000015164811202013480105748 802.pdf>; Acesso em: 19/04/2017.

MADUREIRA, M.A., OLIVEIRA, E., IRVING, M. de A. TAVARES, F. Favela - lugar para se visitar ou evitar? As contradições na mídia sobre o turismo em favelas no Rio de Janeiro. Verso e Reverso, v.31, n.81, setembro-dezembro 2018.

MORIN, E. Introdução ao pensamento complexo. Porto Alegre. Editora Sulina, 2005.

NISBETT, M. Empowering the empowered? Slum tourism and the depoliticization of poverty. Geoforum, v.85, 2017.

OWEN, S. Slumming it: the tourist valorization of urban poverty. Journal of tourism and Cultural Change, v.16, n.2, p.210-212, 2017.

SECRETARIA MUNICIPAL DE URBANISMO - PLANO DIRETOR RIO DE JANEIRO. .Disponível em: < $\quad$ http://www.rio.rj.gov.br/dlstatic/10112/139339/DLFE241269.pdf/Relatorio2009AntecedenteseDiagnostico.pdf>. Acesso em: 19/04/2017

SANTOS, M. A natureza do espaço: técnica e tempo, razão e emoção. Editora Universidade de São Paulo, 2006.

SERRANO, C., BRUHNS, H. T. e LUCHIARI, M. T. D. P. Olhares contemporâneos sobre o turismo. Campinas, SP. Editora Papirus, 2000.

TELLES, A.C. Turismo e pobreza na Era da "Favela Global". Revista Sociedade e Estado - v. 33, Número 1, Janeiro/Abril 2018.

UPP- Unidade de Polícia Pacificadora. Disponível em: < http://www.upprj.com/>. Acesso em: $08 / 10 / 2017$

VALLADARES, L. do P. A invenção da favela: do mito de origem à favela. Rio de Janeiro: Fundação Getúlio Vargas, 2005. 